\title{
Los colores de las conchas marinas en el antiguo occidente de México. El caso del Posclásico
}

\author{
Seashell color in ancient western Mexico. The case of the Postclassic
}

\author{
Luis Gómez-Gastélum
}

Departamento de Estudios Mesoamericanos y Mexicanos, División de Estudios de la Cultura, Centro Universitario de Ciencias Sociales y Humanidades, Universidad de Guadalajara. Apartado postal 39-185, 44171 Guadalajara, Jalisco, México.

gastelum@cencar.udg.mx

Resumen. A partir de los estudios sobre la cosmovisión mesoamericana -en especial aquellos relacionados con el cuerpo humano y las significaciones del color-, se analizan los patrones de uso de las conchas marinas y los objetos elaborados con éstas en las sociedades prehispánicas del occidente de México durante el periodo Posclásico (1100-1350 d.C.), con la finalidad de acercarse al simbolismo que les fueron otorgados por parte de quienes las utilizaron.

Palabras clave: arqueología, entierros humanos, ornamentos, ofrendas funerarias, símbolos, rumbos del universo.

Abstract. Based on studies of Mesoamerican cosmology, especially with regard to the human body and the meaning of color, we analyzed the use patterns of seashells and objects made from seashells in the Pre-Hispanic societies of western Mexico in the Postclassic period (1100-1530 A.D.). The goal was to understand the symbolism given to these objects by the people who utilized them.

Key words: archaeology, human burials, ornaments, funeral offerings, symbols, world quarters.

\section{Introducción}

En México, los estudios de carácter arqueológico referentes a las conchas y caracoles son relativamente recientes en comparación con los que se han hecho en torno a elementos como la cerámica o la lítica. Se han preocupado principalmente por la transformación de las valvas en objetos (Suárez, 1974), su tipología (Suárez, 1977) o las rutas que las llevaron desde las costas hacia los lugares tierra adentro donde fueron utilizadas (Suárez, 1991). Más escasos aún son los que se abocan a explorar su simbolismo (Novella, 1995; Velázquez, 2000), a pesar de que las investigaciones arqueológicas han demostrado la presencia de esos materiales en innumerables yacimientos, desde los más tempranos hasta aquellos contemporáneos a la llegada de los españoles.

Desde tiempos remotos existe una relación privilegiada entre las comunidades humanas y las de moluscos, donde estos últimos sirven como alimento, o bien, sus conchas se utilizan de modo que se vuelven

Recibido: 13 noviembre 2004; aceptado: 28 marzo 2007 parte de la vida cotidiana.

Aquí se realizará un análisis desde la perspectiva de la antropología simbólica que busca un acercamiento a los significados que tuvieron las valvas entre las sociedades del occidente de México durante el periodo previo al contacto con la cultura europea. Para ese momento, esta región cultural es una de las porciones de Mesoamérica y se forma aproximadamente por el territorio que abarcan los actuales estados de Michoacán, Colima, Jalisco, Nayarit y Sinaloa (Fig. 1). En este espacio se desarrollaron diversos pueblos, de los que en algunos casos existen noticias históricas (a través de los escritos coloniales como Acuña, 1988; Alcalá, 1988; Tello, 1968), mientras que en otros sólo se tiene conocimiento por las investigaciones arqueológicas (Carpenter, 1996; Kelly, 1945; Macías, 1990).

El periodo de nuestro interés, Horizonte Posclásico, va desde el año 900 d. C., hasta el momento del arribo de los conquistadores. Se define por sus características militaristas exacerbadas que reconfiguran la geografía política del horizonte anterior -el Clásico- otorgando el control de las sociedades a quienes detentaban el poder castrense. El caso del occidente de México, tiene sus 


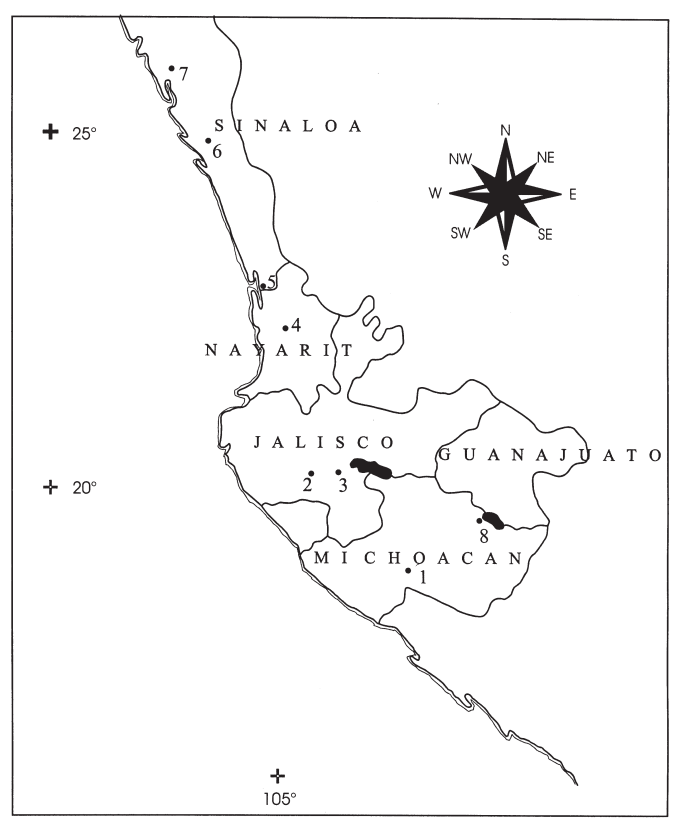

Figura 1. Mapa del occidente de México que ubica los sitios arqueológicos discutidos en el texto. 1. Apatzingán; 2. Tuxcacuesco; 3. Sayula; 4. Amapa; 5. Marismas Nacionales; 6. Culiacán; 7. Guasave; 8. Huandacareo.

propias particularidades. Se caracteriza por la presencia clara de 2 manifestaciones sociales distintas: una serie de sociedades que no alcanzan los niveles de organización estatal, cuyos controles sociopolíticos y económicos son más bien reducidos y la presencia de una sociedad estatal -los tarascos- que logró el dominio de buena parte de la región, consolidándolo principalmente en lo que hoy es el estado de Michoacán, así como porciones de Colima y Jalisco. Es de advertir que la gran mayoría de los desarrollos pertenecientes a este horizonte inician en 1100 y suelen llegar hasta el arribo de los europeos, suceso que en la región ocurre en la década del año 1530.

\section{Materiales y métodos}

Se utilizaron 2 clases de materiales. Por un lado, la información bibliográfica publicada o inédita que estuviera disponible, por otro, se analizaron algunas colecciones de conchas arqueológicas (principalmente procedentes de la región de Jalisco) y, combinando los resultados de ambos, se obtuvo la materia prima para el análisis en cuestión. De sur a norte, se describirán las características que guardan las conchas y sus contextos en las sociedades precolombinas de la región y temporalidad citadas. Primero, de aquellas que no conocieron la intromisión tarasca en su desarrollo y después, las de los propios purépechas.

En el actual estado de Michoacán, durante los años de 1941 y 1942, Isabel Kelly realizó trabajo de campo en la región de Apatzingán. Como parte de su investigación definió varios complejos cerámicos y les otorgó un orden cronológico; al Horizonte Posclásico corresponde el denominado Chila (Kelly, 1947), que corre entre 1100 d.C. y la llegada de los españoles (Schöndube, 1980). La cultura material asociada incluyó conchas y caracoles, por lo que nos abocaremos en aquellas asociadas con los entierros humanos (Fig. 2-A). Éstos corresponden a inhumaciones "flexionadas y sedentes. A menudo con un área circular de ceniza clara bajo la pelvis" (Kelly, 1947), orientadas hacia el norte, oeste o noroeste (Kelly, 1947). Sus ofrendas "fueron depositadas al norte, noroeste o noreste del cuerpo" (Kelly, 1947), consistieron en vasijas y figurillas cerámicas, objetos de cobre y de piedra.

Dentro de los materiales rescatados (Fig. 2-B), se señala la presencia de pendientes de Oliva sp., O. porphyria, Trivia radians y Morum tuberculosum; de sartales hechos con caracolitos de la familia Marginellidae, así como agarraderas de átlatl con especies no identificadas que la autora presenta como "aretes" (Kelly, 1947). Igualmente se registran como valvas sin trabajar, o "dudosamente" trabajadas, las siguientes especies: Trivia solandri, Turritela cf. leucostoma, Oliva sp., Columbella cf. fuscata, Thais sp. y Pinctada sp. Por la cantidad de "asociaciones" registradas, es posible sugerir que las cubiertas pudieron trabajarse localmente (Kelly, 1947). Los elementos contextualizados se presentan en el Cuadro 1.

En lo que hoy es el estado de Jalisco, se han efectuado trabajos en las regiones de Tuxcacuesco y Sayula, en el sur de la entidad. Kelly aporta información de la primera; allí trabajó entre 1939 y 1942. Definió varios complejos cerámicos y temporales interesando aquí el conocido como Tolimán, que tiene los mismos límites que el anterior (Kelly, 1949; Schöndube, 1980). Las inhumaciones de este periodo tienen posiciones extendidas y flexionadas (Fig. 3A), las primeras suelen ser de niños y las últimas de adultos. La orientación de la cabeza es variable, puede apuntar al este, al oeste, al suroeste, al norte o al sur; mientras que las ofrendas son colocadas hacia la cabeza, la pelvis o los pies (Kelly, 1949). Como suele suceder, entre los objetos que acompañan al cuerpo se encuentran artículos cerámicos, líticos y de concha, entre otros.

Kelly indica la existencia de pendientes tallados, de formas geométricas, algunos encontrados en la superficie y otros asociados a entierros (Fig. 3-B). También de brazaletes hechos con Glycymeris sp., quizá G. gigantea. Apunta la utilización del género Spondylus sp., para la elaboración de diversas manufacturas y, la presencia de conchas sin trabajar, que incluyen ejemplares de agua 
A

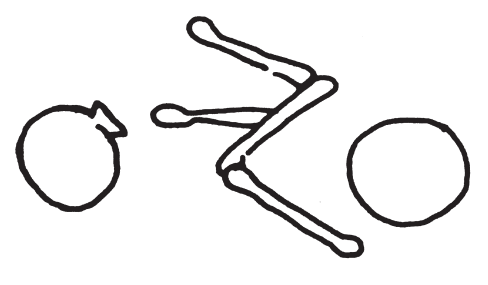

B
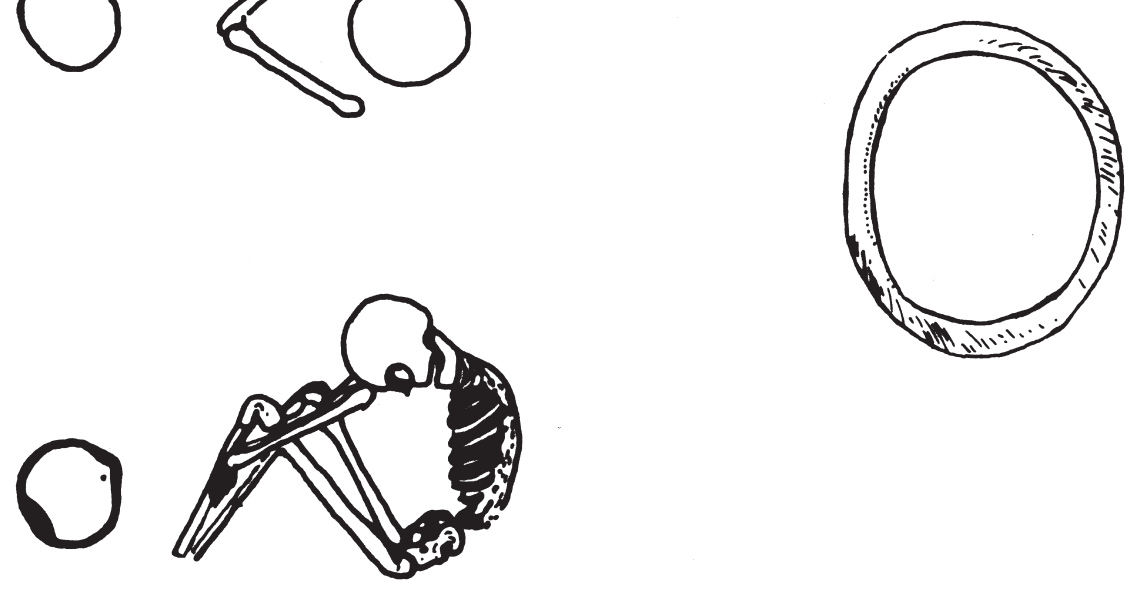

B
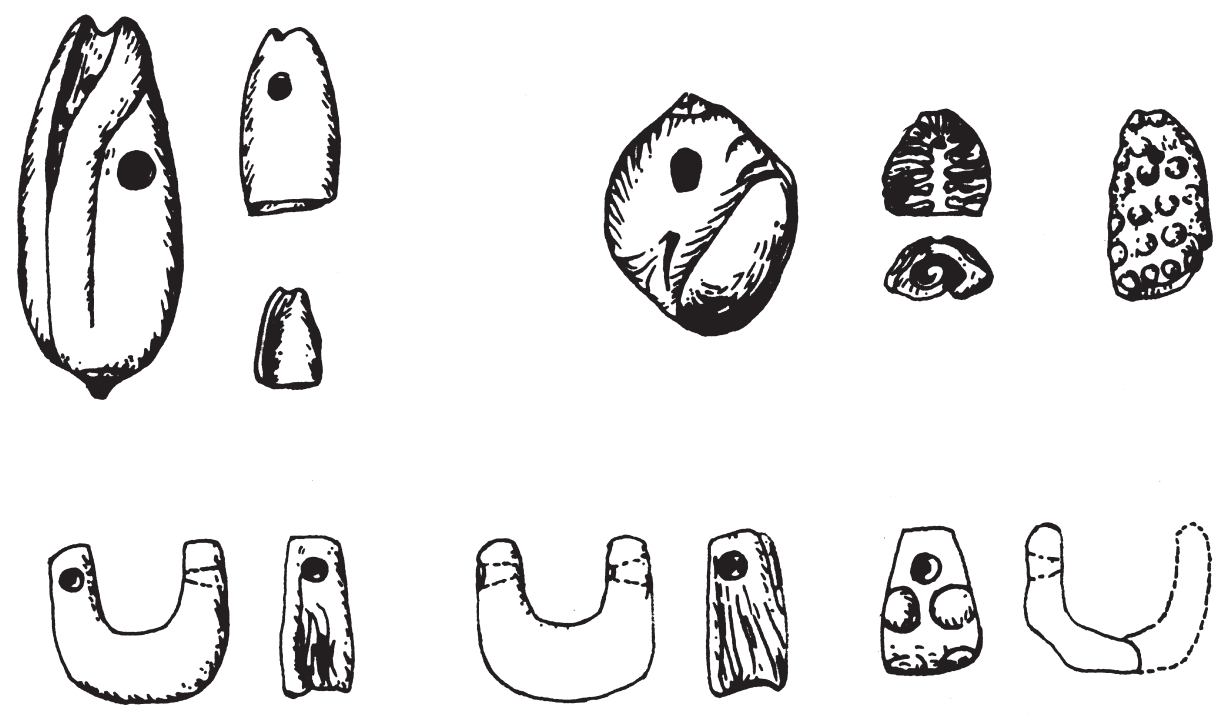

Figura 2. A. Entierros de la fase Chila de Apatzingán, Michoacán; B. Objetos de concha de la misma temporalidad (según Kelly, 1947). 
Cuadro 1. Contexto de los objetos de concha de Apatzingán, Michoacán

\begin{tabular}{|c|c|c|c|c|}
\hline Entierro & Individuo & Objeto & Ubicación & $\begin{array}{l}\text { Identificación } \\
\text { biológica }\end{array}$ \\
\hline 41 & Grupal & $\begin{array}{l}\text { Cuenta tubular } \\
\text { corta }\end{array}$ & Indeterminada & No identificado \\
\hline 44 & Grupal & $\begin{array}{c}\text { Pendiente } \\
\text { Pendiente ovalado } \\
\text { Pendiente } \\
\text { Cuenta disco }\end{array}$ & $\begin{array}{l}\text { Indeterminada para } \\
\text { todas las piezas }\end{array}$ & $\begin{array}{c}\text { Oliva sp. } \\
\text { Valva pelecípodo } \\
\text { Fam. Thaididae o } \\
\text { Muricidae } \\
\text { No identificado }\end{array}$ \\
\hline Ent. B, Yácata 3 & & $\begin{array}{l}\text { Ganchos átlatl } \\
850 \text { cuentas }\end{array}$ & $\begin{array}{l}\text { Indeterminada para } \\
\text { todas las piezas }\end{array}$ & $\begin{array}{c}\text { No identificado } \\
\text { Fam. Marginellidae }\end{array}$ \\
\hline
\end{tabular}

Fuente: Kelly, 1947.

A
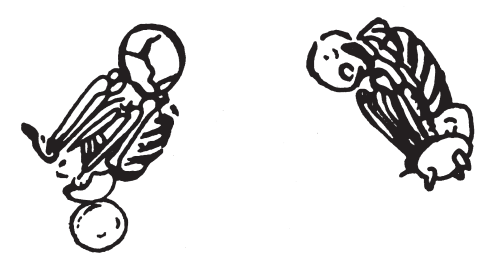

B
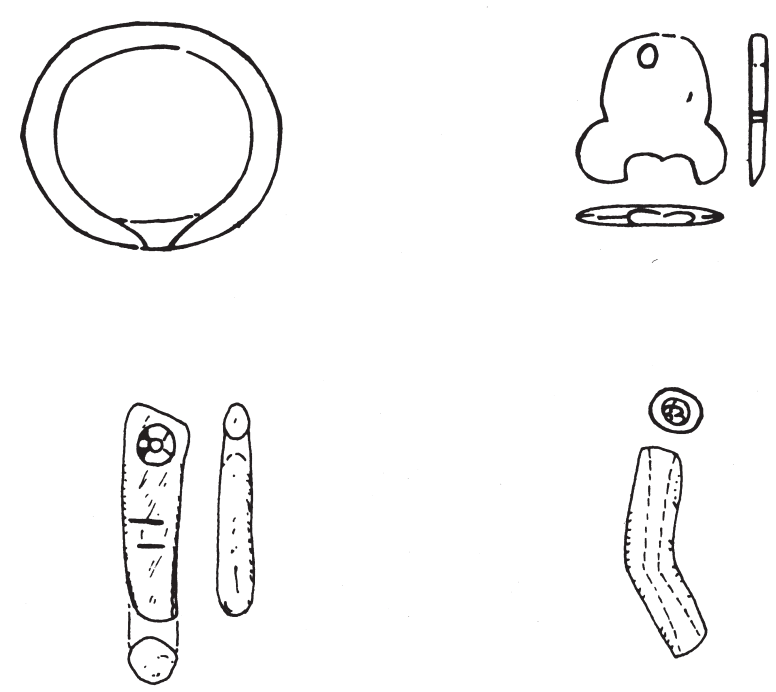

Figura 3. A. Entierros de la fase Tolimán de Tuxcacuesco, Jalisco; B. Objetos de concha de la misma temporalidad (según Kelly, 1949). dulce de la familia Unionidae y del género Unio sp., así como marinos, de las familias Cardiidae, Pectinidae y Veneridae, del género Glycymeris y las especies Pinctada mazatlanica (identificada en el texto como Margaritiphera margaritiphera mazatlanica), Nerita scabricosta, Littorina sp. y Turritela sp. (Kelly, 1949). Los materiales que fueron encontrados en un contexto definido se presentan en el Cuadro 2.

También en el sur de Jalisco se encuentra la cuenca de Sayula, comarca explorada por Kelly y, entre 1990 y 2000, por un equipo franco-mexicano formado por el Instituto Nacional de Antropología e Historia (INAH), la Universidad de Guadalajara y el Instituto Francés de Investigación Científica para el Desarrollo en Cooperación ORSTOM. Los trabajos definieron 4 fases, la última conocida como Amacueca, que corre del año 1100 a 1520 y que con base en el desarrollo cerámico se subdivide en 2: la parte temprana de 1100 a 1300 y la tardía de 1300 a 1520 (Acosta et al., 1998). En los entierros, el cuerpo (Fig. 4-A) se disponía en posición sedente completamente flexionado, con las ofrendas colocadas a los pies cuando las había. En su mayoría los cadáveres fueron ornamentados.

La presencia de artículos de concha entre los entierros es un hecho común (Fig. 4-B). No sólo han sido rescatados entre las inhumaciones, sino también en los sedimentos removidos por las excavaciones y durante los recorridos de superficie. En lo general se registran aretes cuadrangulares con calado central de Spondylus sp., engarzados en aros de cobre; pectorales elaborados en una especie nacarada, probablemente Pinctada mazatlanica; collares y pulseras con sartales de cuentas de Spondylus, o bien, con ejemplares de Olivella sp. o Prunum apicinum; pulseras y pendientes de Glycymeris gigantea, así como sartales de Oliva sp., posiblemente utilizados como cascabeles. Todos 
Cuadro 2. Contexto de los objetos de concha de Tuxcacuesco, Jalisco

\begin{tabular}{cccc}
\hline Entierro & Objeto & Ubicación & Identificación biológica \\
\hline $\begin{array}{c}\text { 34, Potrero del Casco } \\
\text { 1, Montículo B Paso } \\
\text { Real }\end{array}$ & Brazalete & Indeterminada & Glycymeris sp. \\
Pendiente oblongo & Indeterminada & \\
\hline
\end{tabular}

Fuente: Kelly, 1949.

\section{A}

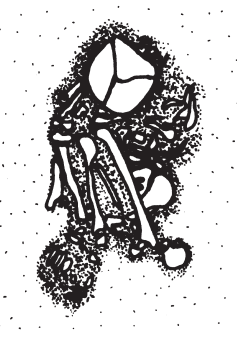

B
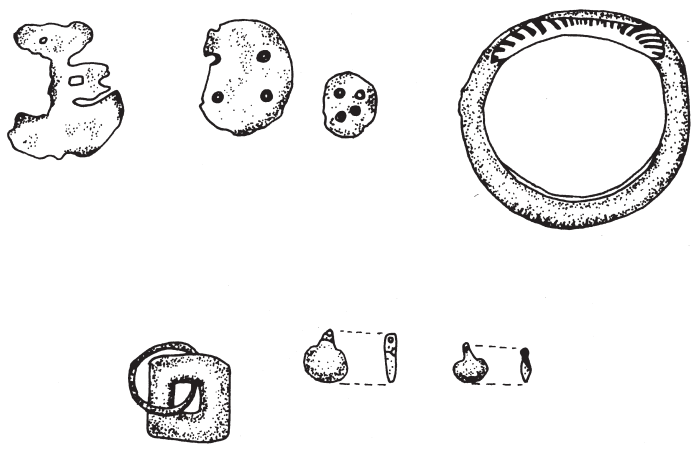

Figura 4. A. Entierro de la fase Amacueca de Sayula, Jalisco (según Acosta 1996a); B. Objetos de concha de dicho periodo.

los géneros y especies proceden de las costas del Pacífico, excepto Prunum apicinum que es caribeña. En contexto, estos elementos aparecen tanto en los entierros del Fraccionamiento San Juan, en Atoyac, como en Caseta. En el primero, que tomaremos como muestra, 9 inhumaciones contaron con objetos de concha y su registro se presenta en el Cuadro 3.

Otros yacimientos de interés son Amapa, en el estado de Nayarit y Marismas Nacionales, una región compartida con Sinaloa. El primero fue investigado a fines de la década de 1950 por un equipo de la University of California at Los Angeles, encabezado por Clement W. Meighan; el segundo por un grupo de la State University of New York at Buffalo, dirigido por Stuart D. Scott entre 1968 y 1978. La temporalidad de Amapa corresponde a sus fases denominadas Ixcuintla y Santiago, la primera entre 1000 y 1300; la segunda, desde 1300 hasta 1400 d. C. Los materiales de concha en Amapa son escasos (Cuadro 4).

Para la segunda región interesa la fase Conchera desde 900/1000 y hasta la llegada de los españoles (Scott y Foster, 2000). Aquí llaman la atención los extensos montículos formados casi exclusivamente por conchas de diversas especies de moluscos. Las valvas asociadas con entierros provienen de 3 sitios: Tecualilla, Chalpa y Panales. En el primero, sólo 5 sepulturas tuvieron objetos de concha que se describen en el Cuadro 5. Chalpa es un sitio formado por numerosos montículos que se extienden por más de kilómetro y medio a lo largo de la línea de playa del estuario (Gill, 1974). Se excavaron al menos 3 elevaciones, denominadas Rasgos A, C y D; en todas se encontraron enterramientos y en conjunto se considerarán como una misma actividad funeraria, ya que presentan atributos comunes, como que estuvieran asociados con Cerithidea montagnei y bolas rojizas al parecer producto de arcilla quemada (Gill, 1974).

Ahora, sobre los entierros y su temporalidad se señala que para los adultos del Rasgo A la posición predominante fue flexionada o semiflexionada, con el cráneo orientado al sur o al oeste (Gill, 1974). De su cronología, se sugiere "una fecha tardía del periodo Tolteca" (Gill, 1974) por la presencia de una hacha de cobre en el Rasgo C, pipas de arcilla y malacates incisos grandes, característicos de la fase Conchera. En este caso hay 4 ejemplos con objetos de concha, 2 en el Rasgo A y los restantes en el D que se exponen en el Cuadro 6.

El último sitio es Panales, donde se excavó en 2 conjuntos de montículos, el B es una elevación baja de tierra, cubierta en uno de sus extremos por un montículo de concha de poco más de $18 \mathrm{~m}$ de alto (Gill, 1974). Aquí se encontraron 4 entierros en malas condiciones, cuyas ofrendas los colocan en una temporalidad aproximada de 1150 d.C. (Gill, 1974); en 2 de ellos hubo elementos de concha que se presentan en el Cuadro 7.

Se hacen ciertas consideraciones en torno a los objetos 
Cuadro 3. Contexto de los objetos de concha de San Juan, Atoyac, Jalisco (Fase Amacueca)

\begin{tabular}{|c|c|c|c|}
\hline Entierro & Objeto & Ubicación & $\begin{array}{l}\text { Identificación } \\
\text { biológica }\end{array}$ \\
\hline 3 & Pulsera & Indeterminada & Anadara sp. \\
\hline 13 & Un pendiente & Indeterminada & Anadara sp. \\
\hline 16 & $\begin{array}{l}3 \text { cuentas circulares } \\
\text { Un pendiente }\end{array}$ & Muñeca derecha & Anadara sp. \\
\hline 17 & $\begin{array}{l}\text { Cuentas circulares } \\
\text { Pendientes }\end{array}$ & Cuello del individuo & Spondylus princeps \\
\hline 63 & $\begin{array}{l}3 \text { aretes (aro de cobre) } \\
\text { Pendientes de concha }\end{array}$ & Omóplato & No identificado \\
\hline 81 & $\begin{array}{c}6 \text { pulseras } \\
12 \text { plaquitas triangulares }\end{array}$ & $\begin{array}{c}\text { Tobillos } \\
\text { Indeterminada }\end{array}$ & $\begin{array}{l}\text { Glycymeris gigantea } \\
\text { Pinctada mazatlanica }\end{array}$ \\
\hline 82 & 3 pendientes semicirculares & Indeterminada & No identificado \\
\hline 95 & 2 cuentas circulares & Indeterminada & No identificado \\
\hline 104 & $\begin{array}{c}3 \text { cuentas circulares pequeñas } \\
14 \text { pendientes }\end{array}$ & Cuello & $\begin{array}{l}\text { No identificado } \\
\text { Natica } \mathrm{sp} . \\
\text { Oliva cf. sayana }\end{array}$ \\
\hline
\end{tabular}

Fuente: Acosta, 1996.

Cuadro 4. Contexto de los objetos de concha de Amapa, Nayarit

\begin{tabular}{|c|c|c|c|}
\hline Entierro & Objeto & Ubicación & $\begin{array}{l}\text { Identificación } \\
\text { Biológica }\end{array}$ \\
\hline Cementerio 2 & 17 fragmentos de brazaletes & Indeterminada & Glycymeris cf. gigantea \\
\hline Cementerio 2 & $\begin{array}{l}\text { Cuentas de disco } \\
\text { Cuentas cuadradas }\end{array}$ & Indeterminada & $\begin{array}{c}\text { Anadara cf. grandis Spondylus } \\
\text { cf. calcifer }\end{array}$ \\
\hline Cementerio 2 & $\begin{array}{l}\text { Cuentas de disco } \\
\text { Cuentas rectangulares }\end{array}$ & Indeterminada & Spondylus calcifer \\
\hline Cementerio 2 & Cuenta de disco & Indeterminada & Pinna rugosa \\
\hline Cementerio 2 & Cuentas de disco & Indeterminada & No identificado \\
\hline Cementerio 2 & Objeto de concha triangular & Indeterminada & No identificado. \\
\hline
\end{tabular}

Fuente: Meighan, 1976.

de concha. Así, se señalan algunas cuentas blancas con forma de diente - un incisivo humano- con perforaciones en el extremo angosto; junto a estas cuentas se encontraron otras más pequeñas (Gill, 1971). Por otro lado, se indica que la mayor parte de los pendientes grandes, de forma triangular o de disco, fueron elaborados con una concha muy densa, rojiza o anaranjada. Para cuentas, se aprovecharon univalvos pequeños, a los que sólo se les hicieron algunas perforaciones para ensartarlas (Gill, 1971).

De Sinaloa hay 2 yacimientos. El primero es Culiacán, explorado en 1935 y 1939 por Kelly. Interesan las fases Culiacán temprano I de ca. 1050 a 1300 d. C., Culiacán medio de ca. 1300 a 1400 d. C. y, Culiacán tardío de 1400 hasta la llegada de los españoles (Schöndube, 1980). Son 
Cuadro 5. Contexto de los objetos de concha del sitio Tecualilla en Marismas Nacionales, Nayarit

\begin{tabular}{ccccc}
\hline Entierro & Individuo & Objeto & Ubicación & $\begin{array}{c}\text { Identificación } \\
\text { Biológica }\end{array}$ \\
\hline $6-\mathrm{B}$ & 1 & Pendiente tallado & Indeterminada & No identificado \\
10 & 1 & 9 cuentas & Indeterminada & No identificado \\
$14-\mathrm{A}$ & 1 & 5 pectorales de concha & Indeterminada & No identificado \\
19 & 1 & Caracol cónico & Entre los dientes & No identificado \\
16 & 1 & Caracoles cónicos & Indeterminada & No identificado \\
23 & 1 & 3 cuentas & Indeterminadas & No identificado \\
$1-\mathrm{A}$ & 1 & 4 cuentas triangulares & Cuello & No identificado \\
\hline
\end{tabular}

Fuente: Gill, 1968; Gill, 1971; Volkmann y Gill, 1970.

Cuadro 6. Contexto de los objetos de concha del sitio Chalpa en Marismas Nacionales, Nayarit

\begin{tabular}{|c|c|c|c|c|}
\hline Entierro & Individuo & Objeto & Ubicación & $\begin{array}{l}\text { Identificación } \\
\text { biológica }\end{array}$ \\
\hline 6, Rasgo A & 1 & $\begin{array}{l}2 \text { cuentas de } \\
\text { concha tallada }\end{array}$ & Indeterminada & No identificado \\
\hline 20, Rasgo A & 1 & $\begin{array}{c}\text { "Concha } \\
\text { puntiaguda" }\end{array}$ & Indeterminada & No identificado \\
\hline 3-A, Rasgo D & 1 & $\begin{array}{l}\text { Muchas cuentas } \\
\text { blancas pequeñas }\end{array}$ & Indeterminada & No identificado \\
\hline 14-A, Rasgo D & 1 & $\begin{array}{l}\text { Un pendiente rojo } \\
4 \text { cuentas con } \\
\text { forma de diente } \\
\text { Muchas cuentas } \\
\text { blancas pequeñas }\end{array}$ & $\begin{array}{l}\text { Indeterminada para } \\
\text { todas las piezas }\end{array}$ & No identificado \\
\hline
\end{tabular}

Fuente: Gill, 1971.

Cuadro 7. Contexto de los objetos de concha del sitio Panales en Marismas Nacionales, Nayarit

\begin{tabular}{ccccc}
\hline Entierro & Individuo & Objeto & Ubicación & $\begin{array}{c}\text { Identificación } \\
\text { biológica }\end{array}$ \\
\hline 3 & 1 & $\begin{array}{c}6 \text { cuentas blancas pequeñas } \\
16 \text { con forma de diente } \\
\text { Cuenta roja tallada }\end{array}$ & Indeterminada & No identificado \\
4 & 1 & Indeterminada & No identificado \\
\hline
\end{tabular}

Fuente: Gill, 1971. 
característicos los entierros en olla; de acuerdo con Kelly (1945) los objetos de concha son escasos (Fig. 5) y habla de brazaletes elaborados con Megapitaria aurantiaca, Chione gnidia y Anadara grandis; de pendientes de Agaronia testacea, Oliva spicata y Polinices recluzianus; además de gusanos marinos del género Serpulorbis sp., para manufacturar cuentas. La única pieza con un contexto bien definido, es un pendiente zoomorfo, al parecer la representación de una rana, en el entierro en olla 47, que podría venir de las excavaciones del sitio Las Lomitas (Kelly, 1945).

El sitio más septentrional sin la presencia tarasca es
Guasave. Fue explorado por Gordon F. Ekholm a finales de la década de 1930 (Ekholm, 1942). Este yacimiento es del periodo Guasave que abarca entre 1000 y 1450 d.C. (Carpenter, 1998). Aquí los cuerpos de los difuntos se disponen de 3 maneras: extendidos sobre la espalda, piernas extendidas y brazos a los lados (Ekholm, 1942); secundarios en fardos, ordenados bultos compactos de todos los huesos largos cubiertos con las costillas, los omóplatos y los innominados, usualmente con el cráneo en la base del fardo, también extendidos (Ekholm, 1942); y por último, secundarios en olla, con el cuerpo desarticulado y los huesos desordenados (Ekholm, 1942), a diferencia de
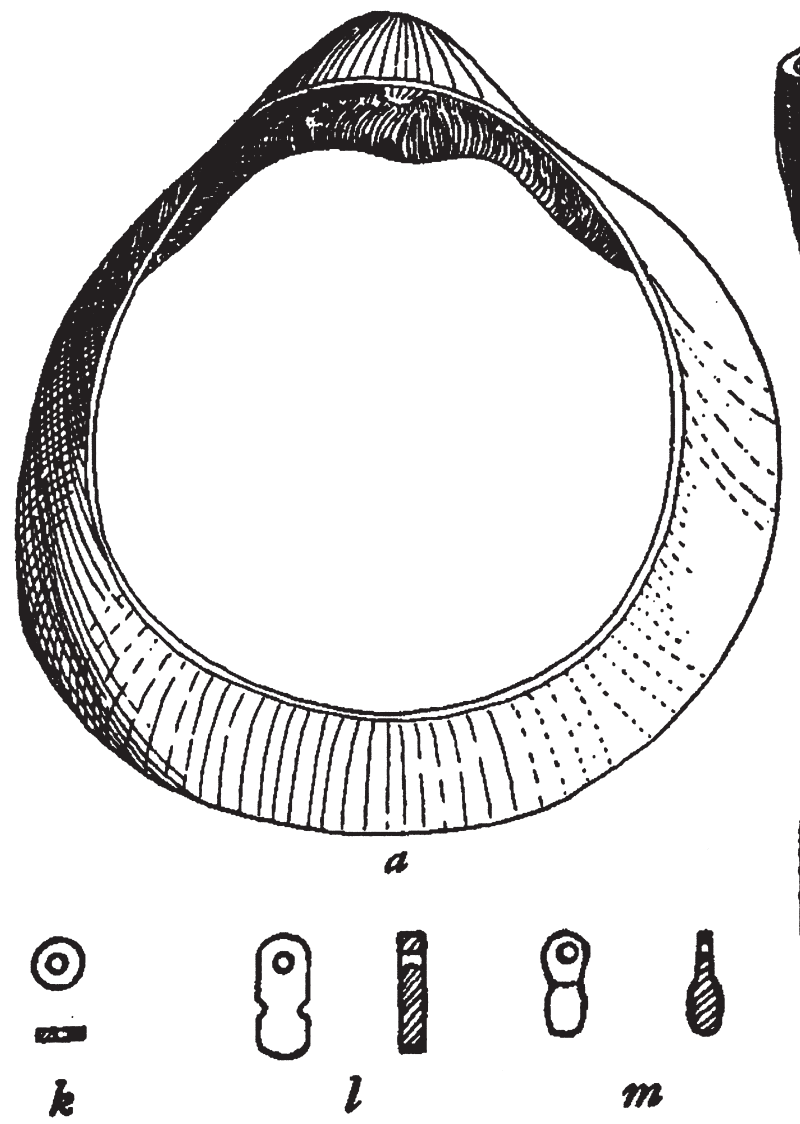

$l$
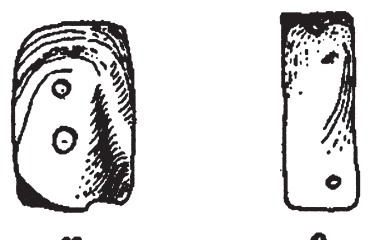

0

$m$

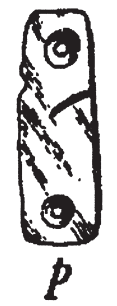

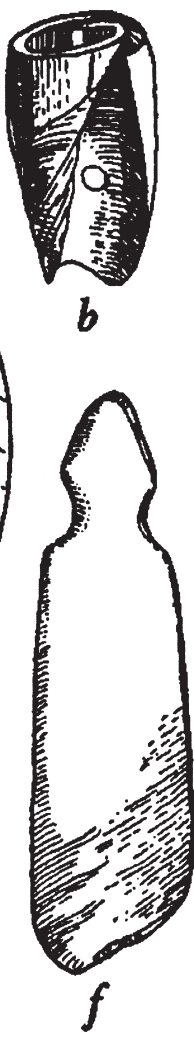
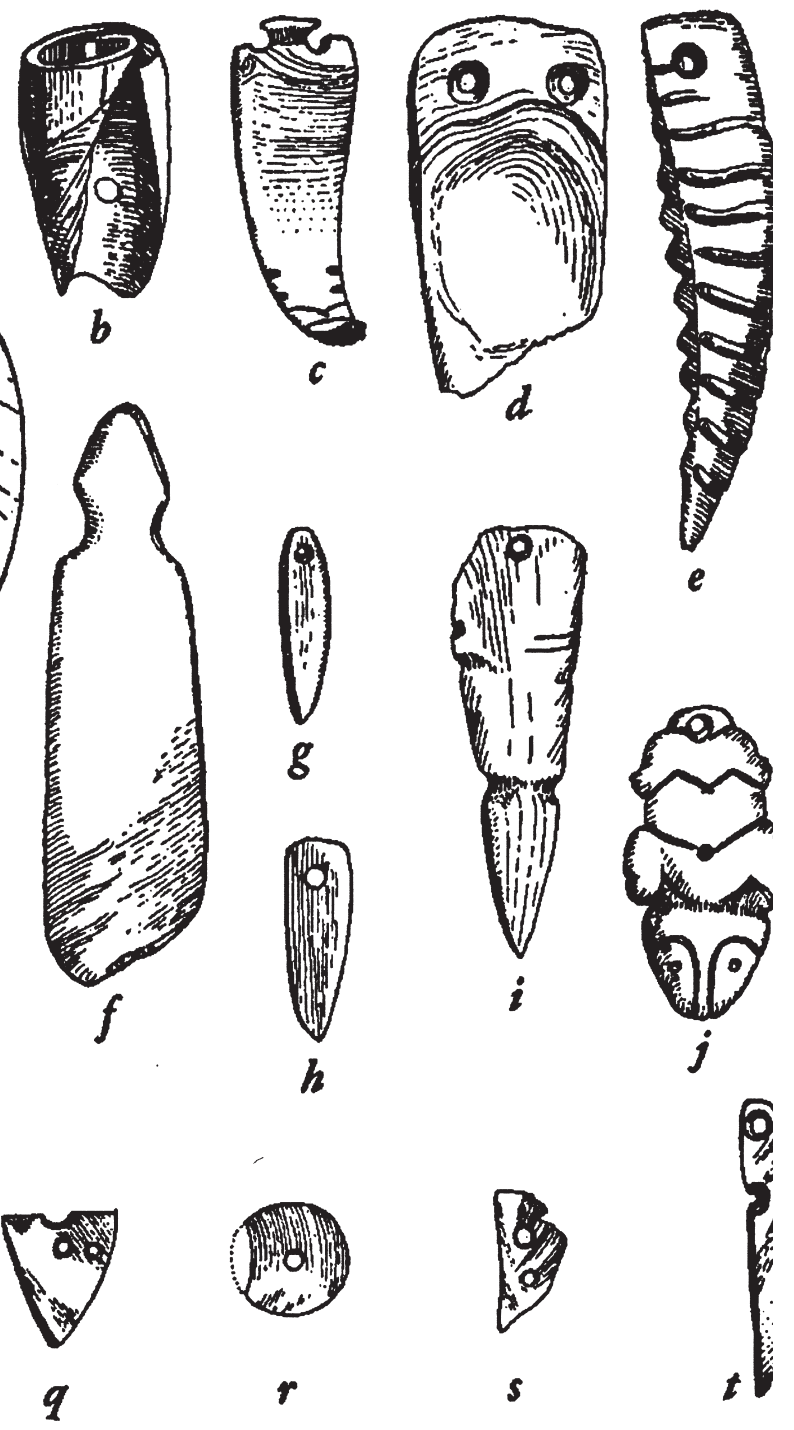

Figura 5. Objetos de concha de las fases Culiacán temprano I, Culiacán medio y Culiacán tardío de Culiacán, Sinaloa (según Kelly, 1945). 
lo que registra Kelly para Culiacán.

En lo que se refiere a los materiales de concha, se mencionan como restos del uso alimenticio de moluscos, principalmente ostiones y almejas, sin indicar los contextos de su hallazgo (Ekholm, 1942). No obstante, lo que llama la atención es su uso como parafernalia de los entierros (Fig. 6). Este material fue abundante y se encontró en forma natural o trabajado como cuentas, pendientes, brazaletes y plaquitas para mosaico. En todos los casos fueron especies disponibles en la localidad (Carpenter, 1996). Cada uno de esos objetos tiene un comportamiento definido en el contexto funerario de recuperación. Así, las cuentas formaron principalmente collares pero también ajorcas [anklets], cinturones y ornamentos cosidos sobre una base de tela (Carpenter, 1996). En estos casos no se identificaron las especies utilizadas. De los brazaletes se señala que "fueron manufacturados principalmente de Glycymeris; sin embargo, al menos uno fue hecho de Laevicardium elatum" (Carpenter, 1996). Los pendientes "consistieron ya sea de conchas completas o cortadas, predominantemente Ostrea sp., con perforaciones para suspensión" (Carpenter, 1996). Por último, en cuanto a la concha sin trabajar, "todas fueron valvas grandes, que incluyen Laevicardium elatum, Anadara grandis y Ostrea sp." (Carpenter, 1996).

Como muestra del uso de las conchas entre los tarascos se encuentran los materiales recuperados por Angelina Macías en Huandacareo, Michoacán, un centro ceremonial ubicado hacia el año 1200 d.C. (Macías, 1990). De los objetos de concha se registran 4 clases de artículos. Primero las cuentas, donde predominan las de disco, aunque se combinan con cilíndricas y de rueda, frecuentemente asociadas con elementos de cobre (Macías, 1990). Luego los pendientes, que la autora (Macías, 1990) coloca en el grupo doce definido por Suárez (1977), formando sartales usados a veces como cinturones. Otros colgantes, aretes quizá, están engarzados en aros de cobre (Macías, 1990). También están los círculos (Fig. 7), que fueron piezas ubicadas en el cráneo, al parecer parte de tocados según lo representado en figurillas de barro antropomorfas (Macías, 1990). Por último están los pectorales, figuras antropomorfas encontradas en conjuntos relacionados con los entierros (Macías, 1990). Los contextos específicos se describen en el Cuadro 8.

En el métodoutilizado se contextualizaron los materiales mediante la observación y registro de su ubicación en el entorno arqueológico. Si se trataba de ornamentos presentes en los entierros, se documentó la relación que tuvieron respecto al cuerpo humano que los portaba. En el caso de las ofrendas, se anotó su ubicación en relación con el continente donde se encontraron. Luego, se procedió a obtener la identificación biológica de las especies utilizadas (hasta donde fue posible), se asentaron el color y la forma de los objetos recuperados. Después vino la interpretación, tratando de responder a la cuestión de si las conchas y caracoles y los objetos con ellos manufacturados podían considerarse como "símbolos de cultura material". Posteriormente, partiendo de los estudios de antropología lingüística sobre los colores de Berlin y Kay (1999), se realizó el agrupamiento de los materiales a partir de sus tonalidades. Por último, utilizando la información sobre la cosmovisión de los pueblos prehispánicos tanto de fuentes coloniales (Alcalá, 1988) como de estudios etnográficos de la región de Jalisco y Nayarit (Lumholtz, 1986), se ofrece una interpretación sobre el significado que pudieron tener estos elementos entre las sociedades precolombinas del occidente de México.

\section{Resultados}

La evidencia disponible reveló que las conchas marinas tienen una clara relación con las sociedades prehispánicas del Posclásico en el occidente de México. Pertenecen a 6 familias marinas -3 de gasterópodos y 3 de pelecípodos-, además de 1 bivalvo de agua dulce; 13 géneros marítimos -8 de caracoles y los restantes de pelecípodos-, 1 bivalvo de agua dulce y 1 gasterópodo terrestre; así como a 24 especies, que incluyen a 17 de caracoles y 9 de bivalvos. En este conteo se exceptuaron aquellos que son desechos alimenticios. Las diversas familias y géneros tienen presencia sobre ambas costas del actual territorio mexicano; en cuanto a las especies, en su gran mayoría se encuentran tanto en la provincia californiana como en la panameña, con excepción de 5 , de las cuales 2 son exclusivas de la panameña, 1 del golfo de California y las 2 restantes provienen de la provincia caribeña (Gómez Gastélum, 2005).

En cuanto a su distribución cultural, sólo 4 géneros y 3 especies tienen una distribución amplia, es decir involucran a más de un sitio o región de los discutidos a lo largo del texto. Los primeros incluyen a Oliva sp., que se encuentra en Apatzingán, Sayula y Huandacareo; Pinctada sp., en Apatzingán y Sayula; además de Glycymeris sp. y Spondylus sp., en Tuxcacuesco y Sayula. Las segundas cuentan con Glycymeris gigantea que tiene presencia en Tuxcacuesco, Sayula, Amapa, Guasave y Huandacareo; Pinctada mazatlanica en Tuxcacuesco, Sayula y Guasave; así como Anadara grandis en Amapa, Culiacán y Guasave. El resto de géneros y especies sólo tiene presencia en un solo yacimiento o región.

Del universo anterior, sólo 3 familias (todas de caracoles), 6 géneros (3 de gasterópodos y 3 de pelecípodos) y 12 especies (repartidas en partes iguales) 


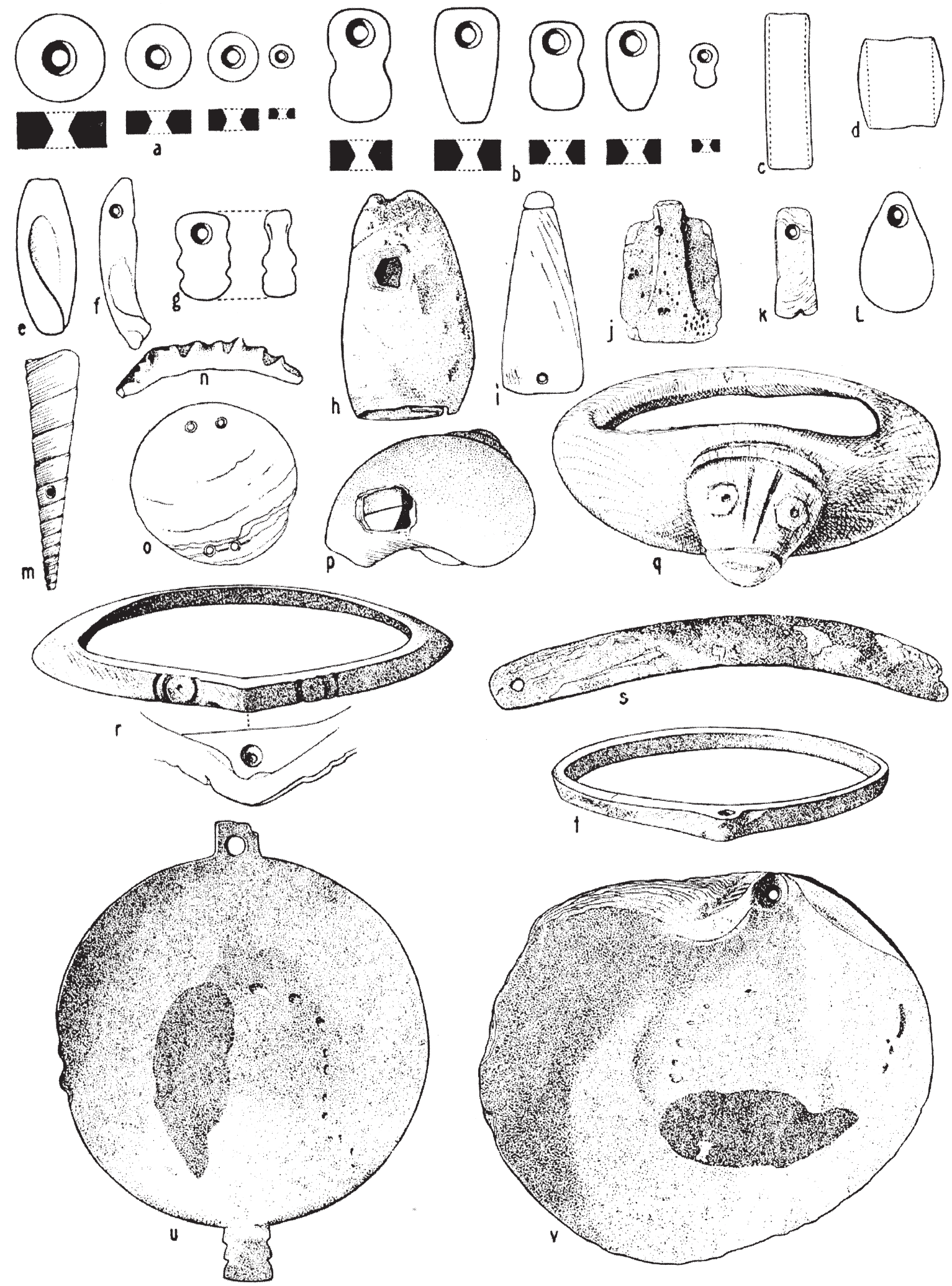

Figura 6. Objetos de concha del periodo Guasave de Guasave, Sinaloa (según Ekholm, 1942). 


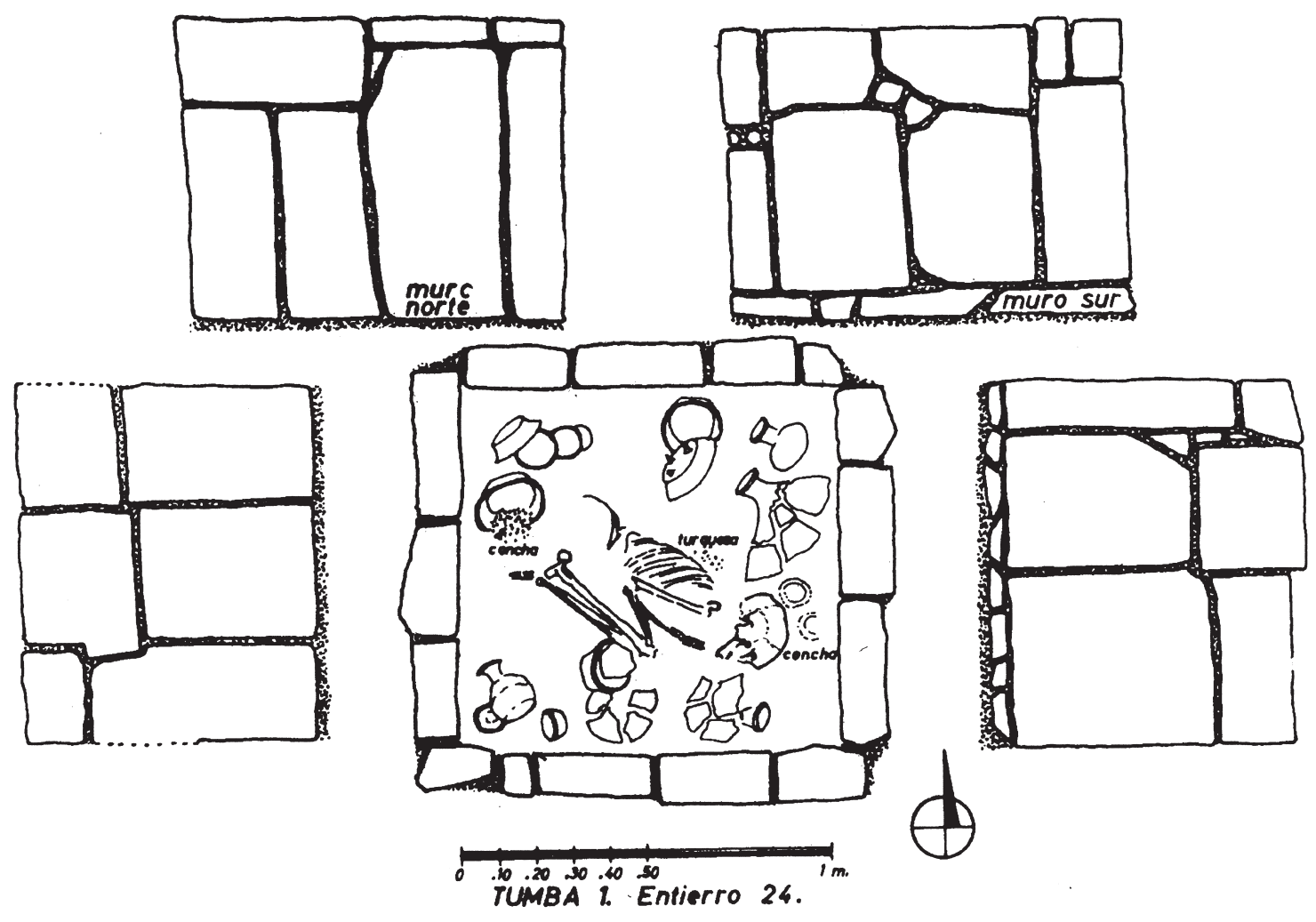

Figura 7. Entierro de Huandacareo, Michoacán, que muestra en contexto los objetos de concha que fueron ofrendados (según Macías, 1990).

fueron registradas en contextos bien definidos, la gran mayoría como parte de entierros humanos, trátese de parafernalia o de ofrenda. Sobre estos elementos se concentrará la atención, ya que cumplen con los requisitos establecidos para que puedan ser considerados como materia prima para un análisis simbólico. En trabajos anteriores se definió que, visto desde la perspectiva de la identificación biológica, no es posible establecer patrones de uso de conchas y caracoles para la época, a la vez que se propuso utilizar otras características para buscar dichas pautas, como serían sus formas y colores (Gómez Gastélum, 2003). Así, al observar sus particularidades, se puede percibir que se agrupan en 6 conjuntos: tonos rojos, iridiscentes, colores claros (blancos y amarillos) moteados en tonos oscuros, blancos, amarillos y, por último, exterior oscuro (café o gris) con interior blanco. Sobre esta base, es posible señalar que todas las conchas son utilizadas como ofrendas y si hablamos de la parafernalia, las cubiertas del primer grupo se encuentran asociadas con la cabeza, cuello y brazos; las del segundo con las piernas y el torso; las del tercero con el cuello, brazos y piernas; el cuarto con la cabeza y el sexto con los brazos.
Profundizando aquello que es relativo a la parafernalia y tomando en cuenta su forma y la relación con el cuerpo, asociados con lacabezase encuentran dos tipos de pendientes (cuadrangulares y oblongos), aretes predominantemente de color rojo, presentes en Huandacareo, Sayula y Guasave. Otros objetos son los ornamentos de tocado, exclusivos de los tarascos en Huandacareo, circulares y blancos. Queda un caracol, encontrado entre los dientes de un individuo en Marismas Nacionales, del cual no se tiene mayor información que la de tener forma cónica. En lo que se refiere al cuello, los artículos típicos son los collares de cuentas (tanto automorfas como xenomorfas) donde predominan tonos rojos, aunque también hay colores claros moteados y están presentes en las regiones de Sayula y Marismas Nacionales.

Pasando al tórax, un sólo ejemplo seguro, un pectoral ovalado iridiscente en Sayula; no obstante, al parecer también hay pectorales en tonos rojos en Marismas Nacionales. En cuanto a los brazos, tienen asociados 3 clases de objetos: brazaletes hechos de una sola pieza elaborados con bivalvos, sartales formados con cuentas bilobuladas y pendientes, muy probablemente utilizados 
Cuadro 8. Contexto de los objetos de concha de Huandacareo, Michoacán

\begin{tabular}{|c|c|c|c|c|}
\hline Entierro & Individuo & Objeto & Ubicación & $\begin{array}{l}\text { Identificación } \\
\text { biológica }\end{array}$ \\
\hline 17 & 1 & Una placa cuadrangular & Indeterminada & No identificado \\
\hline 24 & 1 & $\begin{array}{l}16 \text { fragmentos de } \\
\text { círculos }\end{array}$ & Asociados al cráneo & $\begin{array}{l}\text { Ancistromesus } \\
\text { mexicanus }\end{array}$ \\
\hline 34 & & Pendiente anular & Indeterminada & Oliva sp. \\
\hline $\begin{array}{l}\text { 34-A } \\
\text { ofrenda }\end{array}$ & 1 & $\begin{array}{l}\text { Brazalete de concha } \\
17 \text { pendientes cónicos } \\
\text { Una pulsera anular } \\
\text { Un pendiente cónico }\end{array}$ & $\begin{array}{l}\text { Indeterminada para todas } \\
\text { las piezas }\end{array}$ & $\begin{array}{c}\text { Orthalicus sp. } \\
\text { Glycymeris gigantea } \\
\text { Oliva sp. }\end{array}$ \\
\hline 37 & 1 & $\begin{array}{l}\text { Dos aros de concha } \\
\text { (brazaletes) }\end{array}$ & Bajo el cráneo & $\begin{array}{l}\text { Ancistromesus } \\
\text { mexicanus }\end{array}$ \\
\hline 44 & Múltiple & Columela de caracol & Indeterminada & Fusinus sp. \\
\hline 46 & Múltiple & $\begin{array}{l}\text { Una columela de } \\
\text { gasterópodo }\end{array}$ & Indeterminada & No identificado \\
\hline 48 & & Pendiente anular & Indeterminada & $\begin{array}{l}\text { Ancistromesus } \\
\text { mexicanus }\end{array}$ \\
\hline 50 & Múltiple & $\begin{array}{l}\text { Fragmentos de } \\
\text { caracolitos }\end{array}$ & Indeterminada & No identificado \\
\hline 52 & Múltiple & $\begin{array}{l}2 \text { círculos de concha } \\
30 \text { cuentas de rueda }\end{array}$ & Indeterminada & Bivalvos del Pacífico \\
\hline 60 & Múltiple & 28 pendientes cónicos & Indeterminada & No identificado \\
\hline
\end{tabular}

Fuente: Macías, 1990.

como dijes. Tales artículos muestran diversas tonalidades: rojos, claros moteados, así como exteriores oscuros e interiores blancos, están presentes en Sayula y Guasave. Por último, las piernas cuentan básicamente con las mismas clases de objetos que los brazos, sólo que su ubicación es diferente. Hay ajorcas de una sola pieza y otras formadas por cuentas, en ambos casos al tobillo, que tienen colores claros moteados así como blanco rosáceo. Otro tipo de artefactos son los pendientes zoomorfos (representando pajaritos) en tonalidad iridiscente que están ubicados sobre la tibia. Los objetos de las extremidades inferiores están presentes en Sayula y Guasave.

En lo que se refiere a las ofrendas, es aquí donde existe la mayor variabilidad en todos los aspectos. Destacan las cubiertas sin modificar, tanto de bivalvos como de caracoles, les siguen las cuentas de diversas formas, también hay pendientes zoomorfos (en este caso la representación de la rana) y los brazaletes típicos de la temporalidad. Haciendo referencia a los colores, se tienen todas las tonalidades hasta ahora detectadas. Conchas y caracoles como dádivas funerarias se encuentran presentes en Huandacareo, Amapa, Marismas Nacionales, Culiacán y Guasave.

\section{Discusión}

¿Se pueden considerar símbolos-objeto las conchas arqueológicas? Todo examen que se pretenda simbólico y con mayor razón cuando se busca realizarlo desde la óptica de la cultura material, debe establecer cuáles son los elementos que incluye, cuáles sus características, pero sobre todo sus cargas simbólicas. Un símbolo-objeto se define como la concretización de un símbolo en una entidad tangente, es decir, la materialización de una relación social idealizada representada por aquel (Augé, 1998; Tilley, 1999). Como tal, comparte los modos de funcionamiento de los símbolos no-materiales, a la vez que se convierten en depositarios y guardianes de los significados puestos en ellos gracias a sus propias características (Renfrew y Scarre, 1998; Tilley, 1999). Todas estas particularidades le permiten ser, igualmente, fuente de nuevos significados 
dentro de las tradiciones culturales en las que se encuentran insertos. Dada la definición de nuestro objeto de estudio, queda por establecer si las conchas arqueológicas cumplen con las condiciones para ser consideradas como símbolos-objeto.

La premisa básica que subyace a los símbolos, es la de ser parte de -a la vez que estar enmarcados en- las relaciones sociales. Esto significa que fuera de las sociedades humanas estas manifestaciones no existen $\mathrm{y}$, por lo tanto, el mundo natural (aquel que no necesita de la intervención humana para existir y reproducirse) no simboliza por sí mismo. En el caso de las valvas en el occidente del México prehispánico, podemos señalar en concreto sus características. Primero, estos materiales dejaron el reino natural y entraron al mundo social, lo cual puede apreciarse en los siguientes hechos: en ninguno de los casos examinados, incluidos aquellos yacimientos que se ubican en áreas costeras, la presencia de conchas y caracoles puede ser atribuida a factores naturales. Al contrario, la intervención humana y social fue indispensable para ello, además de claramente visible, ya que la única manera en que las cubiertas llegaron a los contextos de su hallazgo fue a través de un acarreo y acomodo ejecutado por seres humanos.

Segundo, el hecho de que se hayan establecido los patrones ya descritos habla tanto de un uso socialmente aceptado, y tal vez incluso normado por la ritualidad, como de una práctica reiterada a lo largo de la época prehispánica. Esta situación se vincula con la existencia de uno o varios significados presentes en las conchas. $\mathrm{Su}$ presencia constante sin modificar sugiere que estos elementos fueron apreciados por sí, y por lo tanto, a partir de su origen y características, es probable que se les haya asignado una cierta carga significante. La intención de comunicar algo es más clara cuando se habla de los artículos manufacturados con esta materia prima, aquí la valva deja de serlo para convertirse en otra cosa, lo que en principio puede constituir una metáfora al utilizar un elemento para presentar otro distinto. En cualquiera de los casos mencionados, se debe señalar que las características observadas en las cubiertas examinadas se mantuvieron hasta cierto punto constantes a través del tiempo, lo que sugiere que los significados en ellas guardados también pudieron ser duraderos, lo cual es propio de los símbolosobjeto. No obstante, la información arqueológica con que se cuenta solamente nos puede traer hasta este punto, es decir, a vislumbrar las formas de los usos de las conchas marinas, y por lo tanto la respuesta queda incompleta. Para adentrarnos a sus posibles significados es necesario recurrir a otras fuentes y ampliar la óptica del análisis.

Entrevemos ya que las valvas arqueológicas pueden estar desempeñando el papel de símbolos-objeto; sin embargo, la información contextual no puede por sí sola ofrecer la totalidad de la respuesta que se busca. Es por ello que ahora hay que mirar la información que la etnohistoria y la etnografía, tanto de la región como de Mesoamérica en general, pueden ofrecer.

En virtud de las características de las fuentes coloniales tempranas para el occidente de México, y dado que se preocupan poco por ofrecer una visión del mundo indígena, es necesario ampliar el espectro de opciones para obtener la información necesaria. Por tal razón, y asumiendo la posición que postula la unidad de la civilización mesoamericana (López-Austin, 1998) de la cual la región bajo estudio forma parte, se considera que es posible ofrecer explicaciones de los fenómenos particulares de la subárea basados en información procedente de otras regiones de la citada área cultural. Indudablemente, al ser el centro de México la parte mejor estudiada de todo el conjunto, de allí se obtendrán la mayor cantidad de datos; no obstante, no se omitirá la información propia de la porción oeste del país, la que se resaltará cuando esté disponible.

En principio, hay que ver qué fue lo que conchas y caracoles simbolizaron por sí en la cosmovisión mesoamericana. Para los indígenas mesoamericanos prehispánicos, no son desconocidos ni los moluscos ni sus lugares de origen. En cuanto a los marinos, conocían del océano y éste formaba parte integral de su universo, así, para los antiguos nahuas del altiplano central "el mar fue un símbolo de absoluta fertilidad materializada en agua -el término náhuatl para ello fue huey atl, la gran agua, o agua en su forma absoluta. Al mismo tiempo, el mar fue la contraparte necesaria y complemento para la concepción de la tierra y el cielo" (Broda, 1987). Siendo así las cosas, resulta natural que -en principio- todo ente procedente del mar comparta tal simbolismo, es decir la fertilidad. A partir de allí y, de acuerdo con la cosmovisión mesoamericana, se abre un primer gran campo de significación relacionado con los aspectos femeninos, fríos, inferiores, nocturnos, oscuros y acuáticos, que son los correspondientes a la Gran Madre según lo señalado por López-Austin (1996). No obstante, como lo señala Gabriel Espinosa-Pineda (2001): "No toda concha es un ser acuático como otro cualquiera. Debe haber conchas más acuáticas que otras; conchas más celestes que otras; conchas más ligadas a una deidad que a otras; a deidades solares, astrales, terrestres, etc., aunque todas sean conchas".

Otro paso necesario es el recuento rápido y general de los contextos de las valvas y de sus características. Primero, normalmente se les asocia con los entierros humanos, como parafernalia además de ofrenda. Segundo, sus colores parecen tener mayor importancia que cualquier otra característica. Tercero, dentro de los objetos elaborados se destacan algunas formas concretas: 
algunas abstractas, otras antropomorfas y las restantes de animales. Siendo éstas las particularidades y, establecidos en párrafos anteriores los criterios para su examen, es tiempo de revisarlas desde la óptica mesoamericana.

Concordamos con autores como Marc Augé (1998) y Christopher Tilley (1999), quienes consideran el cuerpo humano como fuente de simbolización por sí, además de objeto del simbolismo; igualmente, en la anatomía se puede materializar el universo en el que vive un individuo. La vida, en su faceta individual y en la social, se genera en el cuerpo y abarca todo lo que con éste se relaciona. Para ello es necesario que actúen en conjunto una serie de elementos que en la visión nahua se vinculan con aspectos propiamente biológicos, además de aquellos relacionados con las fuerzas vivificantes (Fig. 8). De acuerdo con López-Austin (1996), entre ellos se encuentran los centros y las entidades anímicas. Un centro anímico es "la parte del organismo humano en la que se supone existe una concentración de fuerzas anímicas, de sustancias vitales $\mathrm{y}$, en la que se generan los impulsos básicos de dirección de los procesos que dan vida y movimiento al organismo y permiten la realización de las funciones psíquicas" (LópezAustin, 1996). Las fuerzas anímicas son tres: el tonalli, el teyolía y el ihíyotl; la primera "es una fuerza que da al individuo vigor, calor, valor y que permite el crecimiento" (López-Austin, 1996) y "está sustancializada en algo que parece ser un aliento" (López-Austin, 1996); a partir de un análisis etimológico -resultado de la indicación que el término náhuatl tléyotl es sinónimo de tonalli-, "y al derivar la palabra tléyotl de tletl, 'fuego', es lógico pensar que su naturaleza era caliente y luminosa" (LópezAustin, 1996). Éste, no obstante encontrarse disperso por todo el cuerpo, se creía principalmente alojado en la cabeza. Y había partes de la anatomía que se consideraban vulnerables con respecto a esta sustancia vital, según el autor: "la manera más directa de comprobar si el tonalli se encuentra en el cuerpo es observar el pulso del paciente, sobre todo en las articulaciones. Por esta misma razón eran las coyunturas sitios propensos al ataque de fuerzas invisibles que succionaban su energía o se introducían en ellas para robar la fuerza vital de la persona" (LópezAustin, 1996).

En lo que respecta al teyolía, era "la entidad anímica que iba al mundo de los muertos" (López-Austin, 1996). A diferencia de la anterior, parece que tiene la particularidad de ser de naturaleza caliente durante la vida del individuo y fría al momento de su deceso, aunque para el siglo XVI sólo se registró que era caliente (López-Austin, 1996); por último, se indica que el asiento del teyolía es el corazón. La tercera entidad anímica, el ihíyotl, "era concebido como un gas luminoso que tenía propiedades de influir sobre otros seres, en particular de atraerlos hacia la persona, animal

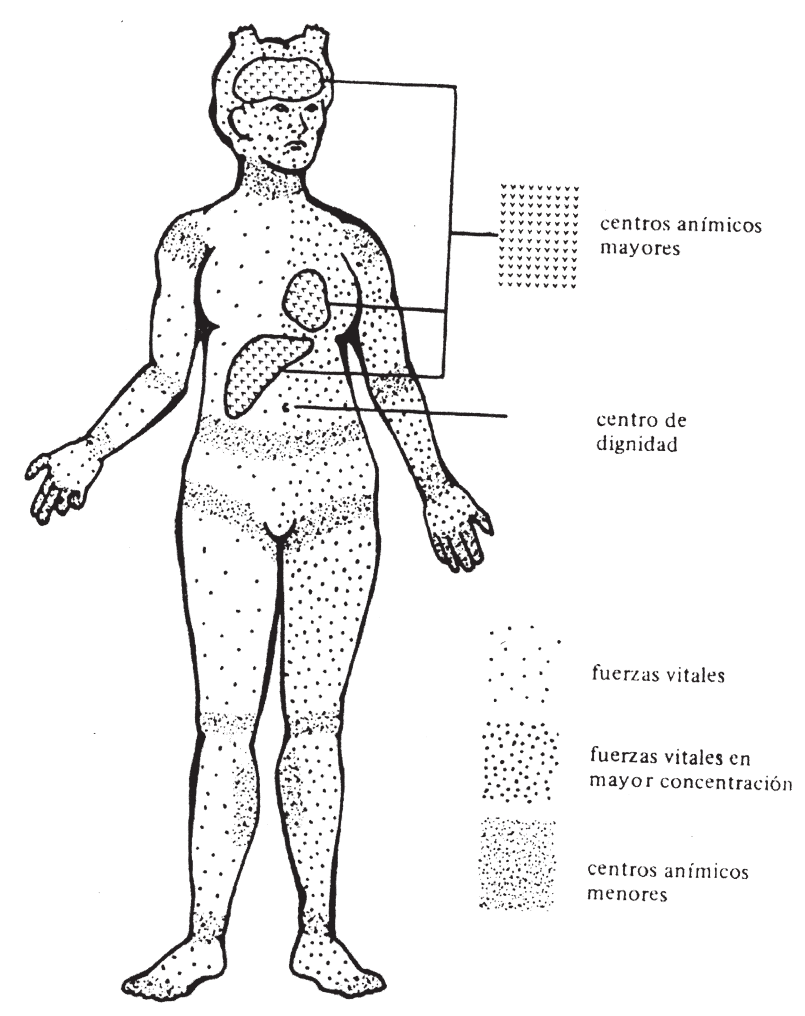

Figura 8. Mapa de las entidades y fuerzas anímicas en el cuerpo humano de acuerdo con las creencias prehispánicas del Altiplano Central (según López Austin, 1996).

u objeto del que emanaba. Hoy lo imaginan los nahuas como un gas frío durante la vida y tras la muerte, informe y difuso" (López-Austin, 1996). Su asiento es el hígado.

Para nuestro interés resultan importantes aquellos aspectos que hacen referencia a la parte exterior del cuerpo, de los cuales en la clasificación de los elementos constituyentes del cuerpo se destacan 3: la cabeza, el ombligo y las pantorrillas. De momento dejemos aquí el tema, pero no sin antes preguntar si todo lo expuesto puede ser aplicado al occidente de México. La respuesta es afirmativa, pues la Relación de Michoacán (Alcalá, 1988) sugiere que en la región existieron las mismas nociones para percibir el cuerpo humano.

Los colores de las conchas fueron una característica de importancia al momento de elegir los ejemplares que serían usados por quienes los portaron. La antropología se ha acercado al análisis cromático desde diferentes perspectivas; principalmente desde la lingüística, mediante un trabajo que esencialmente gira en torno de la propuesta de Berlin y Kay (1999), labor que efectúa un análisis a nivel mundial sobre todo en cuestión teórica. En lo referente a la arqueología, las aportaciones en Mesoamérica con 
respecto a los colores no son especialmente numerosas. Es posible que ello se deba a la costumbre de los arqueólogos de considerar los materiales con que trabajan como meramente "arqueológicos" y no como integrantes de los contextos sistémicos -en términos de Schiffer (1996)- que dicen buscar. No obstante, existen algunas consideraciones en torno al color, como las de H. B. Nicholson, quien señala: "A pesar de las evidentes variaciones regionales y temporales, el simbolismo cromático direccional, que es virtualmente global en su distribución total (Nowotny, 1970), representa quizá el ejemplo estructurado más conciso del empleo del color para expresar conceptos religioso-ritualísticos e ideológicos en Mesoamérica prehispánica" (Nicholson, 1985). Habiendo establecido lo anterior, el autor no va más allá, aunque reconoce que seguramente el asunto debió tener mayor profundidad y complejidad que lo señalado.

Para la región del occidente de México no existe ninguna investigación realizada ex profeso en torno a los colores por ninguna disciplina antropológica. Al respecto, tanto en fuentes históricas como en indagaciones contemporáneas -éstas últimas de carácter etnográficohay cierta información que se encuentra vinculada con aspectos como los rumbos del universo y las geografías rituales (Cuadro 9), las nubes, lluvias y algunos géneros (Cuadro 10), que además cuenta con algunas connotaciones particulares (Cuadro 11).

La presentación sucinta que se ha hecho de los elementos de la cosmovisión mesoamericana es necesaria para ofrecer una interpretación sobre lo que las conchas y caracoles, naturales o modificados, podrían haber significado para los habitantes prehispánicos del occidente de México. A la luz de lo que se observa en la principal asociación de los colores -la de los rumbos del universo-, es necesario efectuar los ajustes pertinentes en los grupos de las conchas, que afectan principalmente su relación con el cuerpo humano. La única modificación es la unificación de los grupos iridiscente y blanquecino en un solo conjunto que denominaremos genéricamente como "blanco". En consecuencia, para el Posclásico tardío las diversas valvas se agrupan en 5 conjuntos (rojos, blancos, amarillos, moteados y exterior oscuro interior blanquecino), donde su ubicación sobre la anatomía humana se manifiesta de la siguiente forma: el primero en la cabeza, cuello y extremidades superiores; el segundo en la cabeza, torso y extremidades inferiores; el cuarto en cuello y extremidades, y el último sobre las extremidades superiores.

Entonces, al prestar atención a las conchas y los objetos con éstas manufacturados, guardando sus características tal y como debieron ser en los contextos sistémicos de los que formaron parte, ¿cómo abordarlas para establecer su simbología? Si partimos de la concepción nahua, al parecer compartida en mayor o menor medida por los diversos pueblos mesoamericanos, en donde el color se observa como inherente al objeto, entonces habrá que considerar esta particularidad como la de mayor peso en el análisis. En ese sentido, se pueden desprender dos niveles para el análisis: uno, las conchas en su conjunto; y dos, las valvas en relación con su contexto particular.

En el patrón de colores que guardan las conchas, en general los que se aprecian son rojo, blanco, amarillo, moteado y exterior oscuro con interior blanquecino. Al comparar esta pauta con los elementos mesoamericanos, resulta una correspondencia con los colores de los rumbos del universo, aquella que tuvieron los tarascos antes del contacto español, si bien esta concordancia excluye al rumbo del centro. No obstante, las principales coincidencias se encuentran cuando uno observa las características del maíz ritual; allí las semejanzas se presentan con los tarascos durante la época prehispánica, pero además con los huicholes ya en tiempos modernos.

Una vez establecidas las relaciones que puedan existir, ¿qué se puede concluir en torno al tema? La consistencia en el conjunto de los colores de las conchas y su vinculación con los rumbos del universo, pero principalmente con el maíz, sugiere muy probablemente una variante de tales asociaciones. No hay que olvidar que los diversos grupos sociales, tanto durante la época prehispánica como en la actualidad, ofrecen información de que dichas tonalidades se encuentran presentes en distintos entes, todos sagrados o fundamentales en las cosmovisiones propias (los mantenimientos, las nubes, las flechas, el peyote y los venados), de manera que cada uno de éstos, a la vez que realzan su propia importancia, simbolizan al universo tal y como fue creado al inicio de los tiempos. Si esto fuera así, entonces estaríamos ante la expresión material de un "símbolo dominante", tal como los entiende Turner (1999), donde éste es la concepción que se tiene sobre la estructura del universo y el patrón cromático de las conchas una de sus expresiones. No obstante, hasta el momento, no hay una mención concreta a las conchas como sí las hay para las entidades mencionadas. Por lo tanto, se habrá de reconocer que ésta queda como una cuestión abierta y es por lo tanto una hipótesis de investigación.

A grandes rasgos, en relación con su contexto en particular, las conchas se encuentran ya sea como ofrenda o como parafernalia, pero siempre como componentes de entierros humanos. En el primero de los casos predominan las conchas y caracoles sin modificar, o bien, que guardan en mucho su forma original. De igual manera, se cuenta con valvas de todos los colores registrados, por lo cual el origen del simbolismo se puede encontrar precisamente en el sistema cromático arriba discutido. Sin embargo, aquí el uso de las valvas no es el del conjunto, sino más bien 
Cuadro 9. Colores y rumbos del universo entre los grupos étnicos del occidente de México

\begin{tabular}{|c|c|c|c|c|c|c|c|}
\hline Grupo/Región & Norte & Sur & Oriente & Poniente & Centro & Arriba & Abajo \\
\hline $\begin{array}{c}\text { Tarascos } \\
\text { (Corona Núñez, } \\
\text { 1993) }\end{array}$ & Amarillo & Negro & Rojo & Blanco & Azul & & \\
\hline $\begin{array}{c}\text { Coras } \\
\text { (Guzmán, 2002) }\end{array}$ & Azul & Amarillo & Rojo & Verde & Verde & & \\
\hline $\begin{array}{c}\text { Huicholes } \\
\text { (Lumholtz, 1986) }\end{array}$ & Blanco & Rojo & Blanco & Negro & & $\begin{array}{l}\text { Azul/ } \\
\text { Verde }\end{array}$ & Café \\
\hline $\begin{array}{l}\text { Huicholes } \\
\text { (Kindl, 2003) }\end{array}$ & $\begin{array}{l}\text { Blanco o } \\
\text { amarillo }\end{array}$ & Azul/Verde & Rojo & Negro & Pinto & & \\
\hline $\begin{array}{l}\text { Huicholes } \\
\text { Las Latas } \\
\text { (Kindl, 2003) }\end{array}$ & Blanco & Azul oscuro & $\begin{array}{c}\text { Rojo/ } \\
\text { Amarillo }\end{array}$ & Negro/Morado & Pinto & & \\
\hline
\end{tabular}

Cuadro 10. Los géneros que tienen colores entre los grupos étnicos del occidente de México

\begin{tabular}{|c|c|c|c|c|c|c|c|}
\hline Grupo/Región & Rojo & Blanco & Amarillo & Negro & Azul/Verde & Pinto & $\begin{array}{l}\text { Asociación } \\
\text { rumbos }\end{array}$ \\
\hline $\begin{array}{c}\text { Tarascos } \\
\text { (Alcalá, 1988) }\end{array}$ & $\begin{array}{l}\text { Chía } \\
\text { Maíz } \\
\text { Flechas } \\
\text { Nubes }\end{array}$ & $\begin{array}{l}\text { Chía } \\
\text { Maíz } \\
\text { Flechas } \\
\text { Nubes }\end{array}$ & $\begin{array}{c}\text { Chía } \\
\text { Maíz } \\
\text { Flechas } \\
\text { Nubes }\end{array}$ & $\begin{array}{l}\text { Chía } \\
\text { Maíz } \\
\text { Flechas } \\
\text { Nubes }\end{array}$ & $\begin{array}{c}\text { Chía } \\
\text { Maíz } \\
\text { Flechas }\end{array}$ & & Sí \\
\hline $\begin{array}{c}\text { Coras } \\
\text { (Guzmán, 2002) }\end{array}$ & Maíz & Maíz & Maíz & Maíz & & Maíz & No especificado \\
\hline $\begin{array}{c}\text { Huicholes } \\
\text { (Lumholtz, 1986) }\end{array}$ & $\begin{array}{l}\text { Nubes } \\
\text { Maíz } \\
\text { Peyote } \\
\text { ¿Chía? }\end{array}$ & $\begin{array}{l}\text { Nubes } \\
\text { Maíz } \\
\text { Peyote } \\
\text { Chía }\end{array}$ & $\begin{array}{l}\text { Nubes } \\
\text { Maíz } \\
\text { Peyote } \\
\text { Chía }\end{array}$ & $\begin{array}{l}\text { Nubes } \\
\text { Maíz } \\
\text { Peyote } \\
\text { Chía }\end{array}$ & Nubes & $\begin{array}{l}\text { Maíz } \\
\text { Peyote } \\
\text { ¿Chía? }\end{array}$ & Sí \\
\hline $\begin{array}{l}\text { Huicholes } \\
\text { (Kindl, 2003) }\end{array}$ & $\begin{array}{c}\text { Maíz } \\
\text { Peyote } \\
\text { Venado }\end{array}$ & $\begin{array}{c}\text { Maíz } \\
\text { Peyote } \\
\text { Venado }\end{array}$ & $\begin{array}{c}\text { Maíz } \\
\text { Peyote } \\
\text { Venado }\end{array}$ & $\begin{array}{c}\text { Maíz } \\
\text { Peyote } \\
\text { Venado }\end{array}$ & & $\begin{array}{l}\text { Maíz } \\
\text { Peyote } \\
\text { Venado }\end{array}$ & Sí \\
\hline
\end{tabular}

se presenta de manera individual. Por tal razón, parece prudente postular que en este caso el fundamento de la simbolización podría estar en los significados de cada tonalidad.

En la parafernalia presente en los entierros es donde resulta muy importante la relación de los objetos de concha con el cuerpo humano. Al observar este aspecto y compararlo con lo que señala López-Austin (1996), en la posición de los moluscos sobre la anatomía humana hay elementos que sugieren que esa posición se presenta por razones que van más allá del argumento meramente funcional que indica: "de aquí se cuelgan porque de aquí pueden colgarse". Los trabajos de este autor han demostrado que hay ciertas partes del cuerpo que tienen particularidades especiales, derivadas de la presencia de las sustancias anímicas, principalmente la cabeza, el cuello, el ombligo y su región, las articulaciones y las pantorrillas, donde se colocan los tocados, aretes, collares, pulseras, brazaletes y cinturones. Las partes mencionadas están fuertemente asociadas con las entidades anímicas, principalmente el tonalli, y las conchas allí se encuentran en pleno contacto con el cuerpo. De tal manera, dadas sus características -principalmente de color y forma- y al ubicarse sobre los centros anímicos, se propone que los objetos de concha pueden estar desempeñando el papel de catalizadores, al fortalecer las entidades anímicas. Esto 
Cuadro 11. Algunos significados de colores entre los grupos étnicos del occidente de México

\begin{tabular}{|c|c|c|c|c|c|}
\hline Grupo/Región & Rojo & Amarillo & Negro & Blanco & $\begin{array}{l}\text { Azul/ } \\
\text { Verde }\end{array}$ \\
\hline $\begin{array}{c}\text { Tarascos } \\
\text { (Alcalá, 1988) }\end{array}$ & $\begin{array}{c}\text { Xaratanga } \\
\text { Deidades del fuego }\end{array}$ & $\begin{array}{l}\text { Oro } \\
\text { Sol }\end{array}$ & Curicaueri & $\begin{array}{l}\text { Curicaueri } \\
\text { Plata } \\
\text { Luna }\end{array}$ & \\
\hline $\begin{array}{l}\text { Coras } \\
\text { (Guzmán, } \\
\text { 2002) }\end{array}$ & $\begin{array}{l}\text { Estrella de la mañana } \\
\text { Prosperidad }\end{array}$ & $\begin{array}{c}\text { Sol } \\
\text { Amanecer } \\
\text { Dios del maíz }\end{array}$ & $\begin{array}{l}\text { Nuestra Madre } \\
\text { Abajo } \\
\text { Dioses del agua }\end{array}$ & $\begin{array}{c}\text { Nuestro Padre Sol } \\
\text { Arriba }\end{array}$ & Tierra \\
\hline $\begin{array}{c}\text { Huicholes } \\
\text { (Lumholtz, } \\
\text { 1986) }\end{array}$ & $\begin{array}{l}\text { Fuego } \\
\text { Vida } \\
\text { Autoridad }\end{array}$ & Fuego & & & \\
\hline $\begin{array}{l}\text { Huicholes } \\
\text { (Kindl, 2003) }\end{array}$ & $\begin{array}{c}\text { Deidades del fuego } \\
\text { Sol } \\
\text { Sequía }\end{array}$ & Atributos solares & $\begin{array}{c}\text { Deidades femeninas } \\
\text { de la lluvia } \\
\text { Oscuridad } \\
\text { Cielo nocturno } \\
\text { Germinación de } \\
\text { semillas } \\
\text { Inframundo } \\
\text { Atrapadores de la vida }\end{array}$ & & Lluvia \\
\hline
\end{tabular}

no sería raro, puesto que el propio autor lo señala: "Ya se ha dicho la relación entre los perfumes y el tonalli. Otros remedios, eran el humo de resinas aromáticas, la carne de las fieras, las drogas psicotrópicas, las joyas" (López-Austin, 1996); y no hay que olvidar que para la época prehispánica, las conchas son y se utilizan para hacer joyas.

Ahora bien, conchas y caracoles se han asociado con los aspectos fríos, femeninos, telúricos y nocturnos de la cosmovisión mesoamericana. De allí que pudiera resultar un tanto contradictorio el uso de conchas para fortalecer el tonalli, sustancia anímica que tiene una esencia caliente, luminosa y solar. No obstante, aquí vuelve a manifestarse la importancia que tiene el color propio de las valvas utilizadas. Resulta interesante, y muy sugerente a la vez, que durante toda la época prehispánica los ornamentos de concha rojizos se encuentren asociados de manera constante con la cabeza, asiento primordial del tonalli. Aunado con lo anterior, la distribución de colores con los rumbos del universo, prácticamente en toda Mesoamérica, el rojo está ligado con la senda del oriente, es decir, el inicio del camino del Sol; está también asociado con la sangre del sacrificio, la fertilidad y el origen de la vida. Todo se integra bastante bien con la idea de la vigorización del tonalli mediante el contacto con esta joyería.

Es posible que también se presenten las asociaciones primigenias de conchas y caracoles, puesto que los blancos y moteados también están sobre la testa. En estos casos, de manera individual, habría que observar con mayor atención la totalidad del contexto, con la finalidad de inferir su simbología. En términos generales, el color blanco y su gama tienen connotaciones claramente lunares, femeninas y de fertilidad; mientras que los moteados suelen ser nocturnos, relacionados con el cielo estrellado y con el inframundo (Graulich, 1999; Sahagún, 1989). Aquí resalta la presencia continua durante la época precolombina de las valvas blancas en su variante iridiscente, que se encuentran sobre el torso, muy probablemente con el significado señalado.

En este nivel es claro que las conchas juegan un papel distinto en términos simbólicos que si las vemos en su conjunto. Aquí estaríamos hablando, más que de símbolos dominantes, tal y como se propuso para el nivel anterior, de la expresión material de una serie de símbolos explicitadores en los términos que los define Ortner (1973). Tal categoría se les asigna tomando en consideración su carácter de joyería, la que sirve para acentuar la diferenciación social, así como las asociaciones particulares de sus colores -que en lo individual parecen comportarse de manera un tanto autónoma del sistema cromático principal, asociado con los rumbos del universo-; rasgos que sirven "para ordenar sentimientos e ideas complejos e indiferenciados, haciéndolos comprensibles para uno mismo, comunicables a los otros y traducibles en acción ordenada" (Ortner, 1973).

A partir de los 2 niveles de análisis propuestos arriba, es posible apreciar que la concha mesoamericana 
presenta el comportamiento general de los símbolos, ya que cuenta con la propiedad de la representación dentro de una relación social. Cuando se le considera en conjunto, puede estar figurando la estructura y origen del universo mesoamericano, pero en el caso de que se le vea en lo individual, teniendo presente color y forma, está personificando diversos aspectos de la cosmovisión prehispánica. Funciona con el mecanismo de los tropos, ya que en dicha representación se observa la metáfora (como en el caso de las conchas rojas que encarnan el fuego, el calor, la fertilidad, etc.), la metonimia (pues al ser consideradas en conjunto, y dadas las diversas variantes que tiene el sistema cromático principal encarnado en los mantenimientos, las flechas y, probablemente, las conchas, permiten utilizar una entidad por otra tomando el signo por la cosa significada) y la sinécdoque (que bajo el mismo principio establecido para la metonimia, está designando un todo utilizando una de sus partes).

Al incorporar todas las figuras trópicas, y al tener una maquinaria compleja que puede utilizarlas simultáneamente, tal patrón puede clasificarse como un ejemplo de la sinécdoque, como la entiende la visión "interaccionista" -definida por Ohnuki-Tierney (1991). De igual manera, cuenta con las cualidades que se indicaron para el símbolo-objeto. Es claro que les han sido depositados una serie de significados que deben transmitir, comportándose como "depósitos simbólicos externos" en términos de la arqueología conductual, mejor definidos por Rawson (1998); y que por su misma materialidad son guardianes, a la vez que fuentes, de los contenidos asignados o de otros nuevos.

\section{Literatura citada}

Acosta-Nieva, R. 1996. Los entierros del sitio San Juan, Atoyac, Jalisco: Los datos primarios. Informe técnico. Departamento de Estudios del Hombre. Universidad de Guadalajara, Guadalajara, Jalisco. 151 p.

Acosta-Nieva, R., S. Ramírez-Urrea y L. Gómez-Gastélum. 1998. Desarrollo sociocultural de la cuenca de Sayula durante la época prehispánica. In El occidente de México: arqueología, historia y medio ambiente. Perspectivas regionales, Ávila, R., J. P. Emphoux, L. G. Gastélum, S. Ramírez, O. Schöndube y F. Valdez (eds.). Universidad de Guadalajara/ORSTOM, Jalisco. p. 101-118.

Acuña, R. (ed.) 1988. Relaciones geográficas del siglo XVI: Nueva Galicia. Universidad Nacional Autónoma de México, México, D. F. 360 p.

Alcalá, J. de. 1988. La relación de Michoacán. Secretaría de Educación Pública, México, D. F. 372 p.
Augé, M. 1998. Dios como objeto. Símbolos-cuerposmaterias-palabras. Gedisa, Barcelona. 143 p.

Berlin, B. y P. Kay. 1999. Basic color terms. Their universality and evolution. CSLI, Stanford, California. $196 \mathrm{p}$.

Broda, J. 1987. The provenience of the offerings: tribute and cosmovision. In The Aztec Templo Mayor: a symposium at Dumbarton Oaks, E. Hill Boone (ed.). Dumbarton Oaks, Washington, D. C. p. 211-256.

Carpenter, J. P. 1996. El ombligo en la labor: differentiation, interaction and integration in prehispanic Sinaloa, Mexico. Ph. D. dissertation, Department of Anthropology, The University of Arizona, Tucson. 461 p.

Carpenter, J. P. 1998. El ombligo en la labor: nuevas perspectivas del sitio de Guasave, Sinaloa. In Antropología e Historia del Occidente de México. XXIV Mesa Redonda de la Sociedad Mexicana de Antropología, R. Brambila Paz (ed.). Sociedad Mexicana de Antropología/Universidad Nacional Autónoma de México, México, D. F. p. 963-984.

Corona Núñez, J. 1993. La religión de los tarascos. In La arqueología en los Anales del Museo Michoacano (épocas I y II), A. Macías Goytia (comp.), L. Mirambell Silva (coord.). Instituto Nacional de Antropología e Historia, México D. F. p. 369-408.

Ekholm, G. F. 1942. Excavations at Guasave, Sinaloa. Anthropological Papers of The American Museum of Natural History, The American Museum of Natural History 38:23-139.

Espinosa-Pineda, G. 2001. La fauna de Ehécatl. In Animales y plantas en la cosmovisión mesoamericana, Y. González Torres (coord.). Plaza y Valdés/Instituto Nacional de Antropología e Historia, México, D. F. p. 255-303.

Gill, G. W. 1968. Human skeletal remains. In Archaeological reconnaissance and excavations in the Marismas Nacionales, Sinaloa and Nayarit, Mexico. Summer, 1968. Preliminary report, S. D. Scott (ed.). State University of New York, Buffalo. p. 153-175.

Gill, G. W. 1971. The prehistoric inhabitants of northern coastal Nayarit: Skeletal analysis and descriptions of burials. Ph. D. dissertation, Department of Anthropology, The University of Kansas, Lawrence. $283 \mathrm{p}$.

Gill, G. W. 1974. Toltec-period burial customs within the Marismas Nacionales of Western Mexico. In The archaeology of West Mexico, B. Bell (ed.). Sociedad de Estudios Avanzados del Occidente de México, Ajijic, Jalisco. p. 83-105.

Gómez Gastélum, L. 2003. Las conchas marinas durante el Postclásico en el antiguo occidente de México. 
Eco, Instituto Jalisciense de Antropología e Historia 4:13-19.

Gómez Gastélum, L. 2005. Conchas y caracoles en el antiguo occidente de México. Un ensayo de antropología simbólica. Tesis de doctorado División de Posgrado, Escuela Nacional de Antropología e Historia, México, D. F. 354 p.

Graulich, M. 1999. Ritos aztecas. Las fiestas de las veintenas. Instituto Nacional Indigenista, México, D. F. 459 p.

Guzmán, A. 2002. Mitote y universo cora. Instituto Nacional de Antropología e Historia y Universidad de Guadalajara, México, D. F. 191 p.

Kelly, I. 1945. Excavations at Culiacán, Sinaloa. University of California Press, Berkeley and Los Angeles. 233 p.

Kelly, I. 1947. Excavations at Apatzingan, Michoacan. Viking Fund, New York. 227 p.

Kelly, I. 1949. The archaeology of the Autlán-Tuxcacuesco area of Jalisco. II: The Tuxcacuesco-Zapotitlán zone. University of California Press, Berkeley and Los Angeles. 292 p.

Kindl, O. 2003. La jícara huichola. Un microcosmos mesoamericano. Instituto Nacional de Antropología e Historia/Universidad de Guadalajara, México, D. F. $289 \mathrm{p}$.

López Austin, A. 1996. Cuerpo humano e ideología. Las concepciones de los antiguos nahuas, 2 vols. Universidad Nacional Autónoma de México, México, D. F.

López Austin, A. 1998. Los mitos del tlacuache. Caminos de la mitología mesoamericana. Universidad Nacional Autónoma de México, México, D. F. 514 p.

Lumholtz, C. 1986. El arte simbólico y decorativo de los huicholes. Instituto Nacional Indigenista, México, D. F. 402 p.

Macías Goytia, A. 1990. Huandacareo: Lugar de juicios, tribunal. Instituto Nacional de Antropología e Historia, México, D. F. 222 p.

Meighan, C. W. 1976. The archaeology of Amapa, Nayarit. University of California, Los Angeles. 506 p.

Nicholson, H. B. 1985. Polychrome on Aztec sculpture. In Painted architecture and polychrome monumental sculpture in Mesoamerica, E. Hill Boone (ed.). Dumbarton Oaks, Washington, D. C. p. 145-171.

Novella, R. A. 1995. Classification and interpretation of marine shells artifacts from Western Mexico. Tempvus reparatvm, Oxford. $110 \mathrm{p}$.

Ohnuki-Tierney, E. 1991. Embedding and transforming polytrope: The monkey as self in Japanese culture. In Beyond metaphor. The theory of tropes in anthropology, J. W. Fernández (ed.). Stanford University Press,
California. p. 159-189.

Ortner, S. B. 1973. On key symbols. American Anthropologist, American Anthropological Association 75:1338-1346.

Rawson, J. 1998. Chinese burial patterns: Sources of information of thought and beliefs. In Cognition and material culture: the archaeology of symbolic storage, C. Renfrew y C. Scarre (eds.). McDonald Institute for Archaeological Research, Cambridge. p. 107-133

Sahagún, B. 1989. Historia general de las cosas de la Nueva España, 2 vols. Consejo Nacional para la Cultura y las Artes/Alianza, México, D. F.

Schiffer, M. B. 1996. Formation processes of the archaeological record. The University of Utah Press, Salt Lake City. 428 p.

Schöndube, O. 1980. Época prehispánica. In Historia de Jalisco. Tomo I. Desde los tiempos prehistóricos hasta finales del siglo XVI, J. M. Muriá (dir.). Unidad Editorial del Gobierno de Jalisco, Guadalajara. p. 111-130.

Scott, S. D. y M. S. Foster. 2000. The prehistory of Mexico's northwest coast: a view from the Marismas Nacionales of Sinaloa and Nayarit. In Greater Mesoamerica. The archaeology of west and northwest Mexico, M. S. Foster y S. Gorenstein (eds.). The University of Utah Press, Salt Lake City. p. 107-135.

Suárez Díez, L. 1974. Técnicas prehispánicas en los objetos de concha. Instituto Nacional de Antropología, México, D. F. 69 p.

Suárez Díez, L. 1977. Tipología de los objetos prehispánicos de concha. Instituto Nacional de Antropología e Historia, México, D. F. 207 p.

Suárez Díez, L. 1991. Conchas y caracoles, ese universo maravilloso. Banpaís., México, D. F. 192 p.

Tello, A. 1968. Crónica miscelánea de la Sancta Provincia de Xalisco. Instituto Jalisciense de Antropología e Historia. Guadalajara, Jalisco. 374 p.

Tilley, C. 1999. Metaphor and material culture. Blackwell, Oxford, England. 298 p.

Turner, V. 1999. La selva de los símbolos. Siglo Veintiuno, México, D. F. 455 p.

Velázquez Castro, A. 2000. El simbolismo de los objetos de concha encontrados en las ofrendas del Templo Mayor de Tenochtitlan. Instituto Nacional de Antropología e Historia, México, D. F. 322 p.

Volkmann, J. E. y G. W. Gill. 1970. Continued excavations at Tecualilla 1970. In Archaeological reconnaisance and excavations in the Marismas Nacionales, Sinaloa and Nayarit, Mexico. Summer, 1970. Preliminary report, S. D. Scott (ed.). State University of New York, Buffalo. p. 45-57. 